\title{
Escrevivência: uma ferramenta metodológica de análise
}

\author{
Escrevivência [live-writing]: a methodological tool
}

\author{
Gabriela Silva Neves; Ana Lucia Coelho Heckert
}

Universidade Federal do Espírito Santo

\section{RESUMO:}

Este artigo é um exercício de escrevivência com o objetivo de analisar as vivências de mulheres negras periféricas. Fizemos uso do paradigma interseccional como ferramenta metodológica de análise da produção das opressões de raça, gênero e classe, bem como as estratégias de enfrentamento. A pesquisa de campo foi feita a partir de rodas de conversas em três Centros de Referência de Assistência Social (CRAS) na capital do Espírito Santo, Vitória. Os CRAS estão localizados no Território do Bem, região periférica da cidade. Os resultados da pesquisa apontaram que as Imagens de Controle como uma ferramenta na produção de discursos violentos que naturalizam a violência contra as mulheres negras. Ressaltamos os exercícios de resistência que as mulheres negras periféricas efetuam e que são construídos a partir desse lugar que ocupa e fabrica estratégias de enfrentamento às diversas violências, criando fissuras nas máquinas produtoras de opressão.

Palavras-chave: Interseccionalidade; Escrevivência; Feminismo Negro; Racismo.

\begin{abstract}
:
This article share an exercise of escrevivência [live-writing] aimed at analyzing the experiences of black periphery women. We resorted to the interseccionality paradigm as a methodological tool to analyze the ways race, gender and class oppression are produced as well as strategies to fight them. The field research was carried out during chat sessions in three Social Service Reference Centers [Centros de Referência de Assistência Social] in the capital of Espírito Santo, Vitória. The CRAS are situated on Território do Bem, one of the periphery regions in the city made up by seven neighbourhoods, namely, Penha, Engenharia, Consolação, Bonfim, Floresta, São Benedito and Jaburu. The results suggest that images of control are used as a significant violence production tool as well as its naturalization against black women through violent naturalizing discourses that affect their bodies. We draw attention to the resistance exercises black periphery women did and which are built upon from this intersection point and forges strategies of struggle against several forms of violence, by cracking the very surfaces of oppression producing machines.
\end{abstract}

Key-words: Intersecctionality; Escrevivência [live-writing]; Black Feminism; Racism.

DOI: 10.12957/mnemosine.2021.61847

\section{Para quem escrevo?}

Maria-Nova queria sempre histórias e mais histórias para sua coleção. Um sentimento, às vezes, lhe vinha. Ela haveria de recontá-las um dia, ainda que não saiba como. Era muita coisa para se guardar dentro de um peito só. 
Meu objetivo na pesquisa vinculada à dissertação intitulada "Escrevivências de Mulheres Negras Periféricas e suas estratégias de enfrentamento contra as opressões interseccionalizadas: as Imagens de Controle e as Necropolíticas" ${ }^{2}$ foi analisar as vivências das mulheres negras periféricas, fazendo uso do paradigma interseccional como ferramenta metodológica de análise da produção das opressões de raça, gênero e classe sobre os corpos dessas mulheres, focalizando também as estratégias de enfrentamento criadas diante da interseccionalidade dessas opressões.

Para tornar essa escrita possível eu compus com algumas mulheres negras periféricas que encontrei durante os dois anos de Mestrado. Acompanhei durante o período de seis meses as reuniões de um grupo de mulheres, negras chamado Obinrin ${ }^{3}$ (Grupo de Estudos e Empoderamento da Mulher Negra), e realizei rodas de conversas em três Centro de Referência de Assistência Social (CRAS) ${ }^{4}$ na cidade de Vitória, capital do Espírito Santo.

O Obirin surgiu em 2016 como uma iniciativa da Secretaria de Assistência Social e do Núcleo Afro Odomodê que é um equipamento da prefeitura de Vitória/ES que trabalha com jovens de 15 a 29 anos numa perspectiva das relações étnico-raciais. Este núcleo foi criado em 2005, vinculado à Secretaria de Direitos Humanos e Trabalho, e está inserido na coordenação de juventude de Vitória.

O Obirin objetiva trabalhar com a perspectiva de raça e gênero visando atrair mais mulheres das comunidades para ocupar o espaço do Núcleo Afro Odomodê, já que o público maior de participantes deste equipamento era de homens negros e jovens. $\mathrm{O}$ Obinrin foi pensado e construído coletivamente com a equipe técnica de assistentes sociais e as participantes do Núcleo, tendo como intuito conversar sobre os assuntos que envolviam seus cotidianos como o racismo, o machismo, o feminismo e o sexismo. Suas integrantes decidiram trabalhar com a história de mulheres negras heroínas, bem como garantir um espaço de conversa e vivência. Desde Dandara até Marielle Franco partimos das experiências dessas mulheres negras que, de alguma forma, subverteram a lógica genocida que lhes foi imposta. Com esse processo somado às nossas experiências, conseguimos tecer uma rede de cuidado e saúde.

O grupo era aberto à participação de todas e todos, independentemente de raça, classe, sexualidade e gênero, mas a prioridade de fala era das mulheres negras. Os encontros aconteciam toda segunda quarta-feira do mês, às $18 \mathrm{~h}$, e pude acompanhá-los ao longo de seis meses. Encontrei no grupo a primorosa conexão com o que eu estudava 
no início do mestrado, mas o grupo foi mudando e, depois de seis meses participando de suas atividades, os encontros foram suspensos.

Sem a possibilidade de continuidade da conexão com o grupo, comecei a fazer outros movimentos buscando meu novo campo de pesquisa. Fiz alguns contatos com o Fórum de Mulheres do Espírito Santo, conversei com algumas pessoas de diferentes coletivos de mulheres para ver a possibilidade de criar um grupo de mulheres negras periféricas, mas em todas as conversas havia grande dificuldade em acessar as mulheres periféricas. Essa dificuldade expressa o quão distante ainda estamos (a Academia) de conseguir dialogar com as mulheres negras que estão fora do circuito da militância e da universidade. Desde o início, o meu objetivo, ou seja, a premissa ético-política fundamental do trabalho de pesquisa, era de trabalhar com mulheres que não conseguiram chegar aos espaços de militância formais ou não tinham acesso aos debates, leituras e movimentos sobre o feminismo negro.

Após alguns meses no grupo comecei a recordar da minha experiência de iniciação científica no CRAS de Campo Verde, em Cariacica, quando eu estava no oitavo período de Psicologia na Universidade Federal do Espírito Santo (UFES). O bairro se situa numa região mais rural da cidade de Cariacica, caracterizada como uma cidade com poucos recursos em comparação à capital, Vitória. Durante o período no ano em que realizei a pesquisa a maioria das pessoas que acompanhei o atendimento desenvolvido era de mulheres negras.

Essa memória me veio à cabeça e foi assim que comecei a ruminar a possibilidade de acessar o CRAS como um meio de alcançar essas mulheres com quem eu tanto queria compor a pesquisa. Após alguns meses dando conta das exigências do Comitê de Ética da Assistência Social (SEMAS) ligado a Gestão Pública Municipal, consegui entrar em três CRAS da cidade de Vitória/ES com a proposta de fazer rodas de conversa para compartilhamento de experiências de mulheres negras.

O uso da pesquisa-intervenção como ferramenta metodológica para a pesquisa permite compreender que o saber é inventado, assim como a realidade é ficção, e estamos produzindo-a o tempo inteiro. Portanto, não se trata de uma busca do que é real, mas sobretudo, dos movimentos de sua produção (HECKERT; PASSOS, 2009). A pesquisa intervenção conversa, interage, integra e se interconecta com a epistemologia feminista negra (COLLINS, 2019), na qual se apoiou esse trabalho. Ela rompe com uma tradição de neutralidade dentro do campo das pesquisas, assim como desconstrói a ideia de que é necessária uma ordem de fatores para se fazer pesquisa, na qual primeiro se aprende sobre 
o fenômeno e depois se desenvolve a pesquisa (HECKERT; PASSOS, 2009). A pesquisa intervenção afirma um aprender-fazendo em que analisamos nossas pertenças como pesquisadores sem o suposto distanciamento sujeito/objeto (HECKERT; PASSOS, 2009). É apostando nesse modo de pesquisar que poderemos continuar criando fissuras nas dinâmicas das estruturas produtoras de opressões, e que permaneceremos nos mantendo na luta que também é cotidiana.

A Epistemologia Feminista Negra também recusa a neutralidade em todas as suas formas e armadilhas ao trazer na centralidade de suas análises as experiências das mulheres negras, bem como a inseparabilidade entre pesquisadora e pesquisa. A conexão desta epistemologia com a pesquisa intervenção foi muito potente na realização deste trabalho, bem como nos caminhos pelos quais me enveredei no ato de pesquisar.

Entendemos que no caminho é que se constrói a pesquisa, e não a priori. Entre o que planejei e o que aconteceu, muita água passou, mudando a direção do rio em diversos momentos. Estar atenta às mudanças que podem alterar o percurso da pesquisa nos ajuda a romper com qualquer perspectiva de controle e de distanciamento pautadas num discurso de neutralidade.

O percurso foi definido pela epistemologia feminista negra ${ }^{5}$ composta por várias intelectuais negras em diáspora e em África que, mesmo possuindo algumas divergências conceituais, mantêm como denominador comum a produção de saberes e análises sobre o mundo a partir das vivências das mulheres negras.

Dentre as semelhanças que atravessaram as produções que encontrei uma que se destacou foi o compromisso com o "como e para quem" estavam escrevendo, e pensando em "quem" precisava ter acesso às suas produções. Todas carregaram a preocupação de se fazerem entender pelas mulheres que não circulam ou não circularam no meio acadêmico. A preocupação de me fazer entender pelas mulheres negras dentro e fora da academia, além da necessidade de fazer o texto circular é algo que eu cultivo desde a escrita do projeto. A pergunta à qual precisei me submeter constantemente ao longo do processo de escrita foi: para quem estou escrevendo e por que estou escrevendo?

\section{Escrevivendo uma trajetória de pesquisa}

Antes de contar um pouco sobre essa trajetória quero afirmar o lugar da minha escrita enquanto periférica, não necessariamente por sua dimensão econômica e/ou numérica, mas desse lugar de experimentações como mulher negra que ocupa um lugar marginal no mundo pautado em um ideal branco. O sentido de periférica neste artigo está 
nesse campo das possibilidades e das potências, uma afirmação da periferia como um espaço de produção, de criação, de inovação, do tensionamento, do enfrentamento, do riso e do choro, do corpo e das relações. É o local que nos permite criar estratégias de enfrentamento às violências produzidas por categorias de raça, gênero e classe (KILOMBA, 2019).

Essa escrita é um exercício de criação de novos discursos e de uma nova linguagem (KILOMBA, 2019) que não necessariamente precisem ser escritos, posto que múltiplas são as formas de produção de saberes que as mulheres negras criaram. Uma escrita que postula a importância de que seja compartilhada pelo corpo que vivencia e que exprime as escrevivências, conceito criado por Conceição Evaristo (2018).

A pesquisa efetuada para a dissertação deriva de muitas escrevivências, de tal forma que extrapolam um texto acadêmico neutro, posto que seus limites não comportariam as muitas cores, as texturas das vozes, os cheiros e o sons das gargalhadas, muito menos o caminho das lágrimas que marcaram os rostos das mulheres negras dessa pesquisa. Por isso me atrevi a escreviver, não com o objetivo de transmitir alguma espécie de realidade do que foi vivido, mas porque é ficcionando que eu encontrei um caminho que fizesse jus à essa experiência.

Para apresentar as histórias que me foram confiadas pelas mulheres negras periféricas que participaram da pesquisa eu contei com o conceito de escrevivência, criado em 1987 por Conceição Evaristo (2018) quando teceu a primeira escrita experimental de uma ficção. A escrevivência é essa experiência de narrar histórias, as histórias que atravessaram minha vivência de mestrado, como ficções da memória que con(fundem) escrita e vida. A própria Evaristo escreve pouco sobre o que é a escrevivência, e muito mais opera com esses conceitos nos diversos contos nos quais ele se apresenta.

A escrevivência não se tornou um conceito meramente ilustrativo/explicativo, mas vivo e operante. Coube a ela a função da linha que conecta cada retalho de pano, tentando ficar atenta aos seus diferentes formatos e texturas, combinando as diferentes cores. Um processo em que, entre a invenção e o acontecimento, me encontrei como autora na possibilidade de criar histórias nas quais cada uma compõe uma coletividade

Escreviver significa, nesse sentido, contar histórias absolutamente particulares, mas que remetem a outras experiências coletivizadas, uma vez que se compreende existir um comum constituinte entre autor/a e protagonista, quer seja por características compartilhadas através de marcadores sociais, quer seja pela experiência vivenciada, ainda que de posições distintas (MACHAD; SOARES, 2017: 206). 
Por isso, ao invés dos diversos conceitos que normalmente são usados no trabalho com narrativas e experiências, escolhi o de 'escrevivência' para falar dessas experiências que são narradas pelas mulheres negras periféricas, que se encontram com as minhas e que, nessa con(fusão), deram vida às oito protagonistas que alinhavaram a pesquisa realizada para a dissertação, são elas: Dama da noite, Cereus, Flor de Maio, Amendoim, Rapudia, Alfinete, Raposa e Sianinha.

Os nomes das protagonistas foram baseados nos nomes populares de diferentes cactos. A escolha se deu pela própria simbologia do cacto ser uma planta que sobrevive a climas extremos, com pouca água e poucos nutrientes, mas que é persistente em continuar a viver e ainda consegue reter muitos nutrientes e água. São plantas vistas como menos formosas e brutas quando comparadas a outras, e não florescem para qualquer um, a qualquer tempo. Nisso reside sua singularidade e, por isso, quando acontece é sempre impactante com suas flores vibrantes, de formas variadas e complexas. A escolha de cada nome-cacto buscou expressar modos singulares de cada protagonista que compartilhou histórias e análises na pesquisa realizada, nas cores, formatos e energia que emanava de cada uma.

Para registro das memórias de cada encontro fiz uso dos diários de campo, uma ferramenta de grande potência que visa romper com qualquer pretensão de neutralidade que possa tentar comparecer no exercício de pesquisar. O diário de campo não é uma escrita intimista, mas uma escrita transversal engajada na vivência da pesquisadora durante o processo de pesquisa. Não pretende traduzir uma realidade, mas compor fragmentos e sentidos da experiência de campo (PEZZATO; L'ABBATE, 2011). Ao revisitar os diários de campo percebi como as histórias compartilhadas ressoavam umas com as outras, mesmo em contextos completamente diferentes. Algumas histórias compartilhadas no Obinrin se assemelhavam com histórias que foram compartilhadas no CRAS de Consolação. Assim como as histórias de minha mãe também reverberaram com algumas histórias no CRAS de Maruípe já as falas das adolescentes do PROJOVEM de Itararé fizeram ecoar algumas das minhas memórias.

O comum produzido em nossas experiências interseccionalizadas pelas opressões de raça, gênero e classe, permitiu a criação dessas distintas protagonistas em que cada uma era uma multidão. Entretanto, não estou aqui afirmando que as histórias e experiências narradas foram idênticas, e por isso passíveis de resumo. Pelo contrário, é como se cada uma fosse um pedaço de pano numa colcha de retalho colorida e diferente, mas, ao mesmo tempo formando ao final uma bela e matizada colcha de retalhos de 
análises sobre o mundo, a partir do olhar da experiência e dos saberes das mulheres negras periféricas.

Enquanto temas em comum podem funcionar como elo entre as vidas das mulheres negras, esses temas serão vivenciados de maneiras diferentes por mulheres negras de diferentes classes, idades, regiões e preferências sexuais, bem como por mulheres em configurações históricas diferentes. Portanto não existe uma cultura das mulheres negras que seja homogênea; existem construções sociais das culturas das mulheres negras que juntas formam a sua cultura (COLLINS, 2016:111).

A escolha metodológica foi um tanto quanto de risco, um tanto quanto de coragem e um tanto quanto de curiosidade. Fui entendendo e apropriando-me da escrevivência no ato de escreviver. E cada vez que eu reescrevia uma das histórias, mais convicta eu ficava de que não poderia ter sido outra a ferramenta metodológica apropriada para a pesquisa que me propus a fazer. Como eu vislumbrava o exercício da descolonização dos saberes e o uso da epistemologia feminista negra, alinhada a uma produção de saberes pautados nas vivências das mulheres negras, vejo que não poderia ter encontrado melhor ferramenta metodológica.

Nas leituras e na pesquisa eu me vi em diversos momentos numa encruzilhada de histórias, memórias e experiências que não eram minhas. Todavia, de alguma forma sentime enredada através das outras histórias que me foram contadas pela minha mãe, pela minha avó, e por outras mulheres que compartilharam comigo vivências e enfrentamentos produzidos pelas opressões de raça, classe e gênero. O que dá vida às escrevivências é essa força coletiva que nos faz imergir nas histórias narradas e sentir que ressoam com a nossa própria história.

As histórias que escrevi podem ser lidas como ficções de memórias, pois como essa memória esquece, nos cabe inventar. Mesmo que as histórias relatem situações ocorridas, ao compartilharem comigo, as mulheres inventaram histórias outras. Porque entre o que vivenciamos e o que narramos há um abismo onde surge a invenção (EVARISTO, 2018).

Um outro conceito que operou junto com as escrevivências foi o da paixão da experiência, a paixão da lembrança, que é como Bell Hooks vai nomear a forma como narramos a experiência de forma retrospectiva a partir da memória e, principalmente, a partir das memórias de sofrimento (HOOKS, 2017):

Seu sentido pode ser facilmente transmitido. $O$ que se perderia na transmissão é o espírito que ordena essas palavras, que declara que por trás delas - por baixo, em todo lugar - há uma realidade vivida. Quando uso a expressão "paixão da experiência", ela engloba muitos sentimentos, mas particularmente o sofrimento, pois existe um 
conhecimento particular que vem do sofrimento. É um modo de conhecer que muitas vezes se expressa por meio do corpo, o que ele conhece, o que foi profundamente inscrito nele pela experiência. Essa complexidade da experiência dificilmente poderá ser declarada e definida a distância (HOOKS, 2017: 124).

As experiências narradas a partir das escrevivências são da ordem dos acontecimentos, elas também foram chamadas de vivências e histórias, todas vividas e narradas por mulheres negras periféricas. Não se trata de um acúmulo, nem de uma simples informação, nossas experiências-vivências narradas aqui são da ordem da raridade. Somos sujeitas da experiência, dispostas a compartilhar o que nos acontece. Na pesquisa realizada foram expostas nossas afetações com a vida, aquilo que sentimos e o que nos ocorre cotidianamente (BONDÍA, 2002).

Essa experiência que não está vinculada ao tempo cronológico, mas ao tempo dos acontecimentos, permitiu que mulheres negras em diferentes momentos da vida, algumas mais jovens, estudantes, e outras aposentadas, algumas mães e outras avós, pudessem dialogar nesta pesquisa. Fui questionada pelas equipes por não delimitar a idade dos grupos, e a razão disso foi justamente tentar proporcionar este encontro de gerações em que a ancestralidade pudesse nos guiar e nos apontar as diferenças e os aprendizados.

A memória, essa ancestral que atravessa a escrita e a linguagem dos povos negros, é corporal, esse mesmo corpo vulnerável à experimentação. Fizemos um trabalho cartográfico com os nossos corpos (de memórias), um exercício ancestral de quem foi privado da própria língua, performamos nossas memórias do corpo a cada encontro (MARTINS, 2003).

Através da escrevivência, da paixão e da experiência, podemos compartilhar nossas histórias sem que nossas experiências precisem ser higienizadas por teorias embranquecedoras e epistemologias que objetifiquem nossas vivências. A afirmação da 'escrevivência' como ferramenta metodológica coloca em xeque a falácia da neutralidade da pesquisa e da distância entre pesquisador e campo. É uma subversão do modo como se produz conhecimento, dentro e fora da academia, justamente por colocar entonação nas vozes, nos cheiros, na comida, no som das risadas, nos olhos marejados, no tom de deboche, entendendo que esses elementos são igualmente importantes para a análise.

\section{A quem cabe falar de violência?}

O primeiro encontro que participei do Obinrin aconteceu no bairro de Itararé, um bairro periférico que faz parte de uma região denominada por seus moradores como Território do Bem. Além do bairro Itararé mais sete bairros fazem parte deste território: 
Bairro da Penha, Engenharia, Consolação, Bonfim, Floresta, São Benedito, e Jaburu. O Território do Bem foi nomeado pelos próprios moradores numa constante luta política pela afirmação da região.

Eu cresci passando os finais de semana no Bairro da Penha, de onde minha mãe e pai vieram. Tenho memórias do pé de manga da minha avó que enlouquecia todo mundo no verão com as enormes mangas-espada que caíam. Ou da manga de vez que a gente cutucava com a vara até cair para comer com sal. Lembro também da caixa d'água da casa da minha madrinha, que era a melhor piscina que eu podia ter no verão.

Minha avó e avô são a minha maior referência no que diz respeito à memória do Território do Bem. Foram uns dos primeiros ocupantes do Bairro da Penha, minha avó tinha dezesseis anos e era recém-casada quando veio para o Espírito Santo nos anos de 1950. Isso corrobora com os dados fornecidos pela prefeitura acerca da ocupação e constituição dos bairros do Território do Bem. Segundo Leite (2009), o primeiro território ocupado foi o bairro Engenharia, em 1920, seguido por Bonfim em 1940, Bairro da Penha na década de 1950, assim como Consolação, Floresta, Jaburu, Itararé e, por último, São Benedito.

A maioria dos moradores era de migrantes oriundos de regiões como o interior do estado do Espírito Santo, tal qual meus avós paternos que vieram de Timbuí, distrito de Fundão/ES. Assim como do sul da Bahia e norte de Minas Gerais, como meus avós maternos que vieram de Resplendor/MG. Segundo Thompson (2014), essa migração aconteceu como consequência das mudanças na economia capixaba com o aumento da produção industrial da cidade e a queda da monocultura do café no interior do estado.

Existe uma escassez de serviços privados e públicos neste território, como o comércio e o transporte público. A maioria das pessoas precisa subir e descer os morros íngremes para acessar os serviços devido às poucas linhas de ônibus que passam nos morros e com trajetos muito limitados. Não nos esqueçamos que essa não deixa de ser uma forma de controle de circulação desses corpos na cidade. Meu avô foi um dos que abriu um negócio no morro e minha avó falava como era difícil conseguir qualquer coisa naquela época, desde um picolé até o acesso à água. Minha avó dizia que quando faltava água no poço de água mais perto de sua casa, ela e outras mulheres e crianças tinham que andar até o outro morro, trazendo o balde com a água na cabeça.

Este território é marcado por um longo histórico de lutas pelo acesso dos direitos fundamentais, como o acesso à moradia e ao transporte público. Tudo que possuem hoje de infraestrutura e de políticas públicas é resultado de longas manifestações, acordos e 
enfrentamento das autoridades.

Em um dos encontros do Obinrin pude estar com um grupo de mulheres negras muito diverso. Minha mãe estava presente e sentadas ao seu lado estavam algumas jovens moradoras do bairro de Itararé, tinha um outro grupo do Bairro da Penha e algumas moradoras do bairro Bonfim chegaram alguns minutos depois. Éramos moradoras da região, integrantes de movimentos sociais, professoras, advogadas, assistentes sociais, sociólogas e psicólogas, estudantes e moradoras de rua. Éramos muitas, mais ou menos quarenta pessoas, todas negras, nas suas diferentes tonalidades, mas majoritariamente retinta. Uma linda paleta de cores, e com certeza uma bela composição de histórias. A proposta foi de fazer uma roda de conversa de compartilhamento de experiências de duas mulheres negras com diferentes trajetórias.

O Obinrin tinha uma aposta de construção de uma política pública que usava como metodologia a interseccionalidade, sem que ela fosse nomeada como tal. Logo de cara senti-me abraçada naquele espaço construído por aquelas mulheres, tantas ressonâncias feitas a cada fala de identificação na experiência narrada uma pela outra. Ver um espaço tão diversificado, mulheres negras com curso superior, outras estudantes de ensino médio, dançarinas, moradoras de rua, atravessando as diferentes faixas etárias, intensificou minhas expectativas em função das dificuldades em realizar um encontro com participantes que tinham inserções e histórias muito diversas. Minha experiência de rodas com mulheres negras não comportavam as mulheres negras periféricas, seja porque aconteciam em territórios onde os seus corpos não eram bem vindos, como a própria universidade, ou porque as pessoas que organizavam não tinham nenhum vínculo com os territórios periféricos.

Infelizmente o Odomodê mudou de lugar e foi instalado na Ilha do Príncipe, outra região periférica, localizada perto do centro de Vitória. A partir dessa mudança os encontros do Obirin passaram a acontecer no parque Pedra da Cebola, situado numa região nobre de Vitória e próximo à UFES. Diferentemente daquele primeiro encontro, menos jovens negras periféricas apareceram, a maioria era estudante universitária ou trabalhadora com formação superior. Os encontros foram muito potentes, deram chão para tudo o que eu estava estudando naquele momento. Porém, as mulheres periféricas que eu tanto queria ouvir e encontrar não estavam ali.

Graças a essas mudanças que foram acontecendo no grupo, comecei a pensar em outras possibilidades de conexões que pudessem me fazer alcançar as mulheres negras periféricas que não circulam em parte dos coletivos e dos movimentos sociais, como 
também da academia. Foi um desafio pensar em uma nova estratégia, porque eram muitas as variáveis e pouco tempo hábil para dar o início formal da realização da pesquisa.

O meu foco continuou sendo o mesmo território. Procurei algumas pessoas ligadas aos movimentos sociais que já tinham feito trabalhos e eventos nestes territórios, e a maioria disse que a principal dificuldade era a entrada no território. Ou seja, a dificuldade era fazer com que as pessoas, mesmo sem te conhecer, participassem das atividades. Quando existia uma grande participação da população, geralmente tinha uma série de entidades e instituiçõoes envolvidas: a escola, as lideranças comunitárias, as ONGs e os movimentos sociais. Sabendo disso tive que pensar em outras estratégias que me poupassem tempo. Tentei entrar em contato com algumas lideranças dos territórios, principalmente de Itararé e Bairro da Penha, porque fiquei sabendo que já existia um grupo de mulheres que se reunia para falar sobre suas vidas e as dificuldades da comunidade. Eu consegui falar com alguns dos contatos, mas disseram que estavam há um tempo sem se reunir. Prometeram que fariam contato comigo tão logo se encontrassem. Nunca recebi outra ligação, mas isso já era de esperar. Afinal, quem eu era? Elas não me conheciam. Qual interesse teriam em ter uma pesquisadora participando do seu grupo? Sinceramente, para elas, não parecia ter muitas vantagens.

Fui ruminando a situação e o tempo foi passando. Quando comecei a recordar as minhas experiências de graduação no Centro de Referência da Assistência Social (CRAS) em Cariacica, uma cidade com bem menos recursos que Vitória, achei que este equipamento poderia ser uma ótima porta de entrada. Afinal, se existe um equipamento público que está inserido nas comunidades periféricas para além da força policial esse é o CRAS.

O CRAS é uma unidade de atenção básica da Política Nacional de Assistência Social (PNAS/ 2004), e está localizado em territórios avaliados como de maior vulnerabilidade social. Sua função é a proteção social básica a partir do acompanhamento das famílias cadastradas, atuando no contexto comunitário do território em que está inserido e oferecendo vários serviços e programas às famílias cadastradas. Dentre estes serviços estão: o Programa de Atenção Integral às Famílias; o programa de inclusão produtiva e os projetos de enfrentamento da pobreza; os serviços de fortalecimento de vínculos familiares e comunitários que são divididos por faixa etária; os Centros de Convivência para Idosos; os serviços socioeducativos para crianças, adolescentes e jovens na faixa etária de 6 a 24 anos; os programas de incentivo ao protagonismo juvenil; os Centros de informação e de educação para o trabalho, voltados para jovens e adultos; 
e os Centros de Convivência para jovens (PROJOVEM) na faixa etária entre 12 e 17 anos (BRASIL, 2005).

Contudo, os CRAS muitas vezes não têm estrutura para ofertar todos os serviços de modo simultâneo. As razões são muitas: 1) falta de estrutura física para comportar os serviços, seja por falta de espaço e/ou de acessibilidade para pessoas com pouca mobilidade. Isso se dá porque a maioria dos CRAS da Grande Vitória foi estruturado em casas e estabelecimentos que tinham outra função no passado, em vez de terem sido construídos conforme a normativa da PNAS; 2) falta de recursos financeiros porque a política de assistência social não conta com definição orçamentária prevista na constituição; 3) falta de trabalhadores, já que muitos dos CRAS trabalham com a equipe muito reduzida e acompanhando um excedente de famílias, muitas vezes o triplo da capacidade prevista pela Norma Operacional Básica NOB/SUAS. Essa foi a realidade que encontrei nos três CRAS de Vitória em que fiz a pesquisa do mestrado, e também no CRAS de Cariacica onde fiz pesquisa de iniciação científica durante a minha graduação em psicologia na UFES.

A escolha de fazer as rodas de conversa no CRAS foi atravessada pela primeira roda de conversa que participei do Obinrin, pois vi um grande conforto das mulheres negras em compartilharem o que estavam vivendo, sempre disparado por alguma história que estava sendo narrada. A decisão de efetuar a pesquisa abrangendo todo o Território do Bem foi muito conflitante, porque isso significaria fazer rodas de conversas em três CRAS diferentes que atendiam a região, a saber: o CRAS de Maruípe, que atendia o Bonfim e também o bairro em que resido, mas que não faz parte do Território do Bem; o CRAS de Itararé que atendia Itararé e o Bairro da Penha; e o CRAS de Consolação que atendia Consolação e Engenharia. Por conta dessa territorialização eu decidi fazer as rodas de conversa nos três CRAS.

Na conversa que tive com o Comitê de Ética da Secretaria de Assistência Social (SEMAS) a primeira coisa que me perguntaram foi se não seria melhor que a minha pesquisa acontecesse no Centro de Referência Especializado de Assistência Social (CREAS) ao invés do CRAS, afinal o CREAS era o equipamento que lidava com violência e violação de direitos. Com essa fala deu para entender o que estamos compreendendo como violência e a quem cabe falar de violência, e não era qualquer violência. Estamos falando de interseccionalidade das violências produzidas pelos atravessamentos de raça, gênero e classe.

Diante da minha afirmação de continuar com a ideia inicial, o comitê me sugeriu 
que eu conversasse com cada CRAS, explicitando qual seria a metodologia das rodas de conversa. Ressaltaram a importância da pesquisa se constituir como uma proposta de construção junto com os equipamentos, respeitando as especificidades de cada território, analisando o que seria possível em cada um, e levando em consideração as dificuldades relacionadas à infraestrutura destes equipamentos sociais.

Durante a primeira conversa com a equipe de Itararé, o comitê de ética indagoume, mais uma vez, se não era melhor fazer a pesquisa no Centro de Referência Especializado de Assistência Social (CREAS). Novamente uma delegação da discussão sobre violência para um outro equipamento, como se não coubesse ao CRAS essas discussões. Novamente expliquei os motivos da minha escolha como uma aposta nos serviços de base, que muitas vezes são a porta de entrada das políticas públicas para muitas famílias periféricas, cujas munícipes, como são chamadas as usuárias dos serviços pelos trabalhadores, são mulheres negras, sendo isso confirmado por todas as equipes. Estas conversas me levaram a indagar como é possível fazer e pensar a política de assistência social sem pensar na interseccionalidade como metodologia de intervenção.

Após as primeiras conversas com as equipes e com o comitê de ética, fiquei muito incomodada com a compreensão de violência como apenas violação de certos direitos, como se não coubesse falar sobre violência no CRAS, sendo que é um equipamento de base e de prevenção. Fiquei indagando-me qual a concepção de violência que permeia esses serviços, pois essa concepção nos limita a não enxergar as violências cotidianas, principalmente aquelas produzidas pela interseccionalidade das opressões contra mulheres negras, porque constroem novas tecnologias a todo o tempo.

Segundo Lapoujade (2015), a violência é inventada, codificada, qualificada e distribuída dentro do campo social, isso a caracteriza como sempre sendo política e estratégica. Não se trata de uma valoração dentro do pensamento dicotômico de mal e bem, mas uma produção. A violência é sempre

[...] um exercício de uma relação de força, força física ou mental, a violência enquanto relações entre corpos (em todos os sentidos da palavra corpo, não apenas corpo físico, mas corpo social ou corpo coletivo). Esse aspecto diz respeito ao poder e às relações entre poderes (LAPOUJADE, 2015: 79).

Outro destaque importante para entendermos o que pode ser a violência, vinculase à compreensão da importância do discurso na sua produção e legitimação, sendo o próprio discurso muitas vezes uma violência (LAPOUJADE, 2015). O discurso tem o papel de legitimar e justificar a violência para que ela seja naturalizada, não apenas pelo Estado, mas nas relações cotidianas. 
Pode-se dizer que eles buscam explicar, legitimar ou justificar os atos de violência. Justificar deve ser tomado aqui no sentido mais literal: é preciso tentar explicar o que um ato de violência contém de justiça. Nesse sentido, justificar deve ser compreendido como verbo milagroso. Ele transforma em justiça aquilo que ele explica. Então se advinha facilmente a finalidade desses discursos: eles querem fazer desaparecer a violência, requalificar a violência como justiça. Não há mais violência, há somente ações de justiça e operações policiais (a serviço da justiça) (LAPOUJADE, 2015: 80).

A condição da mulher negra, ao longo dos séculos, e especialmente no Brasil, vem sendo caracterizada por uma série de violências históricas que foram criando tecnologias para permanecerem atuantes no presente. Desde o período colonial as mulheres negras tiveram seus corpos e dos seus entes queridos explorados, estuprados, mutilados e aniquilados cotidianamente. Hooks (2019) e Davis (2016) relatam algumas experiências brutais que mulheres negras escravizadas vivenciaram desde seus sequestros até as gerações que sobreviveram em terras colonizadas. Alguns desses relatos me fizeram parar a leitura e respirar fundo antes de continuar, minhas pernas balançavam freneticamente enquanto eu lia o mais rápido possível, tentando fugir inutilmente das imagens que foram se formando na minha cabeça. Como explicar o nível de proximidade dessas memórias com o meu corpo? Como lidar com os atravessamentos que essas leituras tiveram sobre este corpo negro e feminizado que vos escreve?

A violência nem sempre é facilmente identificada. A violência cotidiana é também da dimensão do olhar nos lugares em que não somos bem vindas, e está também presente nas piadas e apelidos, na impossibilidade de compartilhar o sofrimento, principalmente os causados pela culpabilização e pelo mito da super potência das mulheres negras, muito explorado pelas imagens de controle.

\section{Imagens de controle de mulheres negras}

Para combatermos as opressões interseccionalizadas contra mulheres negras é preciso desconstruir as imagens de controle que nos são impostas. Segundo Collins (2019), tais imagens são ferramentas de poder utilizadas pelos grupos dominantes desde o período colonial para naturalizar e justificar a permanência das violências contra mulheres negras. Por isso, um dos objetivos do pensamento feminista negro é combater essas imagens.

Uma das funções das imagens de controle é a de transformar as mulheres negras em objetos, negando-lhes a condição de sujeitos (COLLINS, 2019). Utilizam-se da mídia, da literatura e das artes para ensinar e naturalizar o que foi traçado como destino para as mulheres negras. Como Fanon (2008) aponta a este respeito, ao analisar os efeitos na 
produção de histórias que construíram a imagem do preto agressivo e selvagem, enquanto o herói e o aventureiro da história era o menino branco, fazendo com que crianças brancas e negras se identificassem com o personagem heroico branco, ao mesmo tempo em que passavam a temer o preto selvagem.

Ao indagar como inicia o processo traumático da criança negra, ele analisa que ela pode começar bem antes do seu contato direto com o branco através da literatura, dos jornais, do cinema, da televisão imagens de controle são propagadas o tempo todo. Seja ela criando uma imagem da pessoa branca como a vencedora a heroína que é inteligente bonita, que não possui limites pela natureza branca. Enquanto a pessoa negra quando retratada é a servente, ou a louca, ou a perigosa. Passa-se a rejeitar a si mesmo (FANON, 2008: 130-131).

A noção do Outro é fundamental para a construção das imagens de controle. Primeiro porque o processo de objetificação se dá de forma binária, no qual o diferente é o oposto, é o objeto inferior. E esse é um exercício constante no processo de dominação, por isso a análise dessas imagens são fundamentais para compreender as especificidades do processo de objetificação das mulheres negras. As opressões de gênero, raça e classe são interseccionalizadas, e fazem parte da base das opressões interseccionais as hierarquias, as objetificações e o pensamento binário (COLLINS, 2019).

Uma vez colocadas no lugar de objetos não é possível se autodefinir ou falar sobre si mesmo. González (1984) analisa os processos de infantilização das mulheres negras que têm como objetivo nosso silenciamento e domesticação. Colocam-nos sempre no lugar das faladas por todos, mas sem o direito de falarmos por nós mesmas. E o risco que assumimos aqui é o do ato de falar com todas as implicações. Exatamente porque temos sido faladas, infantilizadas (infans, é aquele que não tem fala própria, é a criança que se fala na terceira pessoa, porque falada pelos adultos), que neste trabalho assumimos nossa própria fala. Ou seja, o lixo vai falar, e numa boa (GONZÁLEZ, 1984: 225).

Como aponta Fanon (2008), para o preto há sempre um mito solidamente enraizado a ser combatido. Lélia González (1984) analisa o mito da democracia racial como uma forma de ocultamento das opressões. E ocultamento exerce violências que atingem especialmente a mulher negra, porque ao mesmo tempo que temos a glamourização da mulher negra no carnaval, como a figura da globeleza que também corresponde à imagem de controle da mulata, temos a imagem de controle da puta. E fora desse contexto, quando voltamos para o cotidiano, ela se transforma na imagem de controle da empregada doméstica. Podemos afirmar que as imagens de controle da mulata e da doméstica "são atribuições de um mesmo sujeito" (GONZÁLEZ, 1984, p. 228) e o que as diferenciará será seu contexto. 
$\mathrm{Na}$ pesquisa de campo que realizamos as imagens de controle que compuseram e se expressaram nas escrevivências das protagonistas do texto construído foram: a imagem de controle da Tia Anastácia, da empregada doméstica e da mammy, ou seja a mãe preta; a imagem de controle da mulata; e a imagem de controle da puta.

Essas imagens de controle expressam algumas das violências que encontramos nas escrevivências das protagonistas e que causavam estranheza aos gerentes dos serviços do CRAS, sem que fossem devidamente discutidas em um equipamento de proteção e prevenção. Ao encaminhar tais questões preferencialmente para acompanhamento do CREAS se reitera a compreensão de que a violência é principalmente física, e que há um lugar específico para que sejam debatidas e trabalhadas, sem considerar a proximidade geográfica e existencial das mulheres com os serviços. Diríamos que lugar de debater e trabalhar a violência vivida pelas mulheres negras é onde elas definem e se sentem menos constrangidas.

Em todas as conversas que estabeleci com as mulheres negras, em todos os casos, tinha uma sabedoria que eu descreveria como muito palpável e entrelaçada com o dia a dia. Um saber construído na troca com outras mulheres e nas vivências que acumulavam, uma sagacidade que não é natural, é inventada e acumulativa, e não opcional. Essa sabedoria vinha de uma necessidade de sobrevivência, de si mesma e dos próximos. Essa é a chave para criar estratégias de enfrentamento às opressões interseccionais que apenas com o conhecimento acadêmico não seria possível (COLLINS, 2019).

A epistemologia feminista negra é construída alinhavada à essa produção de saber, que difere do modo de produção do saber científico que é pautado na neutralidade. Esta epistemologia usa sempre como parâmetro a produção do saber efetuado nas experiências das mulheres negras, na sua forma de viver e enxergar o mundo, essa é a sabedoria coletiva cultivada no pensamento feminista negro. Entendemos que este é um diferencial fundamental na construção do pensamento feminista negro, ao lutar por espaço na produção de conhecimento invocamos “[...] as experiências vividas como critério de credibilidade" (COLLINS, 2019: 411).

Apesar de Collins (2019) trazer em suas análises o contexto estadunidense e suas elaborações irem ao encontro de muitas das produções das intelectuais negras brasileiras, é preciso tomarmos cuidado ao utilizarmos o pensamento das intelectuais negras de forma colonizadora em relação ao Brasil. Como aponta Akotirene (2018), existe uma conexão transatlântica nas experiências das mulheres negra em diáspora. Uma das conexões produzidas pelas experiências e produções das mulheres negras em diáspora é a 
interseccionalidade.

A necessidade de criar esse conceito surgiu quando Crenshaw (1989) deparou-se com uma grande brecha na interpretação das leis que deixavam as mulheres negras desamparadas contra as colisões das discriminações de gênero, raça e classe, posto que eram discriminações analisadas separadamente e de forma hierarquizada. Ao criticar as análises hierarquizadas, a autora propõe a 'interseccionalidade' como uma ferramenta de análise baseada no que denomina de avenidas identitárias que produzem eixos de discriminações quando se cruzam. Segundo esta autora as mulheres negras são atingidas pelo tráfego das avenidas de raça, de gênero e de classe (CRENSHAW, 2004).

Crenshaw (2004) utiliza o termo interseccionalidade também para apontar as complexidades que envolvem suas lutas e pautas, porque não há como a mulher negra, enquanto sujeito histórico e político, lutar sem levar em consideração as interseções das diferentes opressões que a atinge. Akotirene (2018: 14) confirma essa perspectiva quando propõe que "a interseccionalidade permite-nos enxergar a colisão das estruturas, a interação simultânea das avenidas identitárias”.

Essa é uma pauta histórica dentro do feminismo negro. Desde os anos 50 no mundo, e especificamente nos anos 70 no Brasil, o movimento feminista branco universalizou a categoria de mulher, ignorando todas as marcas causadas pelo colonialismo na vida das mulheres negras (RIBEIRO, 2016). Por muito tempo não houve espaço dentro dos movimentos de luta negro e feminista em que as complexidades da vivência que a mulher negra sofre ocupasse parte da pauta das lutas feministas. É fundamental para as mulheres negras a compreensão de que as dimensões de classe, raça, sexualidade fazem com que as diferentes mulheres passem por experiências complexas de violências. Por isso é necessário enegrecermos as pautas feministas e, ao mesmo tempo, feminizarmos as pautas dos movimentos negros. Esta é uma luta antiga e necessária das mulheres negras, lutas que não se descolam de suas vidas (CARNEIRO, 2005).

Tanto o sexismo quanto o racismo se institucionalizaram no Brasil a partir da colonização como nova ordem social e política (HOOKS, 2019). Neste momento, as categorias de raça e gênero surgiram como "eixos fundamentais ao longo dos quais as pessoas foram exploradas, e sociedades, estratificadas" (OYEWÙMÌ, 2004: 1), ficando nítido com a análise das experiências das mulheres negras no período escravocrata.

O estupro é um grande exemplo que reverbera até os dias atuais sobre como o sexismo e o racismo atingem o corpo da mulher negra de forma interseccionalizada. Os 
constantes estupros de mulheres negras faziam parte da rotina das lavouras, eram usados como um instrumento para subjugar as mulheres escravizadas e, de quebra, ainda tentar destruir qualquer desejo "de resistir e, nesse processo, desmoralizar seus companheiros" (DAVIS, 2016: p. 36). Quando era conveniente, as mulheres negras escravizadas eram exploradas pelo seu trabalho da mesma forma que os homens, e quando convinha ao senhor, eram abusadas e punidas de forma que apenas poderiam ser infligidos às mulheres e reduzindo-as à "condição de fêmea" (DAVIS, 2016: 19).

As mulheres negras eram materializadas no lugar do Outro e encontramos no racismo diferentes características que nos ajudam a defini-lo. De acordo com Kilomba (2016), a construção do outro como diferente é o primeiro passo para entender que existem uns e os Outros. Fanon (2008) vai falar sobre a invenção do negro pelos brancos europeus como essa oposição a tudo o que diz respeito à brancura. Sendo assim, ao negro, o Outro, é atribuído tudo o que é da ordem da selvageria e da perversão, enquanto o branco assume a condição de humano para si. Essa é a base que sustenta o racismo anti-negro e que vai construir uma série de imagens de controle de mulheres negras. $\mathrm{O}$ racismo constrói o lugar do Outro, do diferente da norma branca. A segunda característica nos mostra que essa diferença é valorativa e hierárquica, ou seja, o diferente está sempre aquém daquele que está na norma branca, e a terceira e última característica é que se trata também de poder, sendo ele econômico, histórico, político e social (KILOMBA, 2019). É no exercício do poder e da diferenciação hierárquica que de um lado da moeda o racismo é moldado e, do outro lado, a supremacia branca (KILOMBA, 2016).

Muitos conceitos feministas estão enraizados sobre a família nuclear que é, por condição, generificada, ou seja, centrada na divisão de gênero. Seu foco está na relação do casal, marido e esposa, depois da prole (OYĚWÙMÍ, 2004), sendo esse o modelo universalizante de família propagado e naturalizado pelo brancocentrismo. Por isso, OyěwùmÍ faz um alerta pelo modo com que esses conceitos chegam de forma colonizadoras em territórios africanos, ignorando as construções sociais e os saberes locais (AKOTIRENE, 2018).

É no modelo de família nuclear brancocêntrico que a mulher é reduzida ao papel de esposa, e a própria maternidade está vinculada à presença do homem. Isso fica muito nítido quando nós nos referimos às mulheres com filhos e sem companheiro como mães solteiras, criando desqualificações sobre essa mãe supostamente incompleta. É um discurso muito comum dentro dos diferentes equipamentos públicos, e eu o encontrei também no CRAS. Ele se fazia presente no revirar de olhos das profissionais quando 
estavam ouvindo as repetidas queixas daquelas mulheres ou quando as chamavam de irresponsáveis por não conseguirem cuidar dos filhos. A imagem da mulher negra que é mãe e não possui um marido é rapidamente vinculada a um erro, um problema social e, por isso, muitas vezes tratada como tal pelos serviços públicos.

\section{Resistências e invenções na negritude}

Davis (2016) mostra como as mulheres negras foram importantes peças para a resistência da população negra, durante e depois da escravidão. Ela indica que as mulheres negras escravizadas abriram espaço para a luta e as conquistas não só para elas, como para toda a comunidade negra e para todas as mulheres. Seja na luta antiescravagista, pelos direitos civis e/ou pelo acesso à educação, as mulheres negras sempre estiveram à frente dessas lutas, mesmo que fossem as últimas beneficiárias e que ficassem apagadas da história como se suas presenças não tivessem surtido efeito.

Nossas histórias são marcadas pela construção de estratégias e muita força de vida. O que é distinto do estereótipo do corpo preto que tudo aguenta. É uma força criativa que nos fez criar a 'abayomi' como forma de produzir afeto e resistência, em meio a um cenário de completa privação e de violências constantes e das mais diversas.

Collins (2016) escreve sobre a marginalização das mulheres negras nos ambientes acadêmicos, apontando como as intelectuais negras fazem uso desse lugar marginal de forma criativa. As outsiders within, conseguem analisar as relações sociais em que estão inseridas com um olhar que se difere do pensamento acadêmico hegemônico. Ela usa esse conceito para explicar que o pensamento feminista negro não foi construído por mulheres negras acadêmicas, mas sim com os saberes de mulheres negras ao longo da história, mulheres como Cereus, Sianinha e Raposa. Como sinaliza a autora, "O pensamento feminista negro consiste em ideias produzidas por mulheres negras que elucidam um ponto de vista de e para mulheres negras" (COLLINS, 2019: p. 101).

Muitos discursos hegemônicos reduzem as mulheres negras a uma imagem de vítimas, muitas vezes de sua própria ignorância em relação ao que se passa em sua vida (WERNECK, 2005). Todavia, as protagonistas mostraram-se outsider within sempre, não apenas analisando as violências interseccionalizadas, como também criando novos caminhos para um futuro menos opressor.

Kilomba (2019) fala acerca da máscara do silenciamento, mostrando seus usos como forma de controle e dominação dos povos africanos escravizados nas Américas. Ela analisa por que o mais temível de todos os nossos órgãos é a boca, e o medo que o branco 
colonizador tem de ser confrontado com a sua própria crueldade e terror de si mesmo a partir da fala de negros e de negras submetidos à desumanização. A recusa de se identificar nesse lugar de opressor é utilizada para manter as práticas e estruturas violentas que produziram e que são colocadas no campo do esquecimento. Nesse processo, o grande inimigo, o Outro, é criado como contraponto ao "eu” branco.

A cada roda de conversa em Consolação, não importava como eu estava, mas saía energizada e mais forte do que antes. Aquelas mulheres irradiavam uma força, muito diferente de uma superpotência atrelada às imagens de controle, mas uma força que vinha da fragilidade que deixavam fluir naquele pequeno espaço que criamos. Muito dessa força vinha da capacidade de autodefinição que traziam em cada fala e gesto. A autodefinição, conceito criado por Collins (2019), aponta a capacidade das mulheres negras de enfrentarem as opressões e, ao mesmo tempo, criar novas possibilidades além daquelas impostas pelas máquinas opressoras.

Assumir nossa fala para nós mesmas é imprescindível nesse processo de enfrentamento das opressões e, principalmente das imagens de controle. Por isso, Collins (2019) cria dois conceitos importantes para nossa compreensão das estratégias de enfrentamento. A autodefinição é o enfrentamento "do processo de validação do conhecimento político" que embasa as imagens de controle (COLLINS, 2016: 102). O poder de autodefinição não é uma opção para as mulheres negras, é um processo necessário para sobreviverem em meio às opressões (COLLINS, 2019). Essa tecnologia é coletiva e faz parte da nossa história, nos ajudando a enxergar, analisar e enfrentar as opressões de raça, gênero e classe.

Além disso, se, ao mesmo tempo, as mulheres negras usarem todos os recursos disponíveis - seus papéis como mães, sua participação nas Igrejas, seu apoio mútuo no seio de redes de mulheres negras, sua expressão criativa - para serem autodefinidas e autoavaliadas e para encorajarem outras a rejeitarem a objetificação, seu comportamento cotidiano será uma forma de ativismo. Pessoas que se veem como plenamente humanas, como sujeitos, se tornam ativistas, não importa quão limitada seja a esfera de seu ativismo. Ao devolverem a subjetividade às mulheres negras, as feministas negras lhe devolvem também o ativismo (COLLINS, 2016:114).

O que significa colocar a história em uma peneira (GONZÁLEZ, 1984)? O que fazíamos nas rodas de conversas era passar um pente fino na história hegemônica que nos foi contada e resgatar as mulheres que foram omitidas das memórias que constantemente tentam apagar e anular. E nesse processo fomos afinando nossas forças enquanto mulheres negras que também são ignoradas no nosso cotidiano. 
A resistência vivida por essas mulheres é maquínica e inventiva. As abayomi, bonecas de espiga de milho, os usos da raiva, a oralidade construída pelas Ialodês e presentes nas rodas de conversas, são potências criativas na produção de outros modos de viver (HECKERT, 2004; ROLNIK; GUATTARI, 1996). A resistência está presente nas estratégias da vida cotidiana das mulheres negras, sempre como num exercício de potência de ação (HECKERT, 2004). Não está limitada a uma reação à dominação ou a opressão. Pelo contrário, são as nossas resistências que vem primeiro, por isso a máquina capitalística sempre tenta capturar e serializar nossas invenções, mas sempre encontramos formas de escapar, criamos desvios à toda forma de opressão (DELEUZE; GUATTARI, 2012).

Conceição Evaristo (2018) nos ensina a escreviver e trazer nossas sabedorias ancestrais tecidas no nosso cotidiano para transmitir às novas gerações nossas vozes libertárias. Nossa ação de resistência se faz na luta por exercícios de liberdade, em lutas pelo direito de governar nossa própria vida e autodefinir nossa existência. Retiramos nossas máscaras de silenciamento (KILOMBA, 2019) e com nossas vozes queimaremos tudo que nos imponha uma condição de vida subalterna, criando outros modos de existir.

Finalizo com o poema de Conceição Evaristo (2008) intitulado Vozes Mulheres, afirmando a escrevivência como um exercício de resistência de mulheres negras:

\author{
A voz de minha bisavó \\ ecoou criança \\ nos porões do navio. \\ ecoou lamentos \\ de uma infância perdida. \\ A voz de minha avó \\ ecoou obediência \\ aos brancos-donos de tudo. \\ A voz de minha mãe \\ ecoou baixinho revolta \\ no fundo das cozinhas alheias \\ debaixo das trouxas \\ roupagens sujas dos brancos \\ pelo caminho empoeirado \\ rumo à favela. \\ A minha voz ainda \\ ecoa versos perplexos \\ com rimas de sangue \\ e fome. \\ A voz de minha filha \\ recolhe todas as nossas vozes
}


recolhe em si

as vozes mudas caladas

engasgadas nas gargantas.

A voz de minha filha

recolhe em si

a fala e o ato.

O ontem-o hoje - o agora.

Na voz de minha filha

se fará ouvir a ressonância

o eco da vida-liberdade.

\section{Referências}

AKOTIRENE, Carla. O que é interseccionalidade? $1^{\mathrm{a}}$. Ed. Belo Horizonte - MG: Letramento, 2018.

BONDÍA, Jorge Larrosa. Notas sobre a experiência e o saber da experiência. Revista Brasileira de Educação, no 19, 2002.

BRASIL. Política Nacional de Assistência Social - PNAS/2004; Norma Operacional Básica - NOB/Suas. Brasília: Ministério do Desenvolvimento Social e Combate à Fome - Secretaria Nacional de Assistência Social, 2005.

CARNEIRO, Sueli. Ennegrecer al feminismo. In: CURIEL, Ochy et al, Feminismos disidentes en América Latina y el Caribe. Ediciones fem-elibros, vol 24, $\mathrm{n}^{\circ} 2$. 2005.

COLLINS, Patricia. Hill. Pensamento feminista negro. São Paulo: Boitempo, 2019.

COLLINS, Patricia. Hill. Aprendendo com a outsider within: a significação sociológica do pensamento feminista negro. Soc. estado., Brasília , v. 31, n. 1, p. 99127, Apr. 2016. Acesso em 28/09/2018: $<$ http://www.scielo.br/scielo.php?script=sci_arttext\&pid=S0102$69922016000100099 \& \operatorname{lng}=$ en\&nrm=iso $>$.

CRENSHAW, Kimberlé. A intersecionalidade na discriminação de raça e gênero. Cruzamento: raça e gênero. Unifem, Brasília, 2004.

CRENSHAW, Kimberlé. Demarginalizing the Intersection of Race and Sex: A Black Feminist Critique of Antidiscrimination Doctrine, Feminist Theory and Antiracist Politics. University of Chicago Legal Forum: Vol. 1989: Iss. 1, Article 8, 1989.

DAVIS, Angela. Mulheres, raça e classe. 1ª ed. São Paulo: Boitempo, 2016.

DELEUZE, Gilles.; GUATTARI, Felix. Mil platôs: capitalismo e esquizofrenia. Vol. 3 São Paulo: Editora 34, 2012

EVARISTO, Conceição. Poemas da recordação e outros movimentos. Belo Horizonte: Nandyala, 2008.

EVARISTO, Conceição. Becos da Memória. Rio de Janeiro. Pallas: Fundação Biblioteca Nacional, 2018. 
FANON, Franz. Pele negra, máscaras brancas. Salvador: Edufba, 2008.

GONZÁLEZ, Lélia. Racismo e sexismo na cultura brasileira. Revista Ciências Sociais Hoje, Anpocs, 1984.

GUATTARI, Felix.; ROLNIK, Suelly. Micropolítica: cartografias do desejo. Petrópolis: Vozes, 1996.

HECKERT, Ana Lúcia Coelho. Narrativas de resistências: educação e políticas. 2004. 311 f. Tese (Doutorado em Educação). Universidade Federal Fluminense, Niterói, 2004.

HERCKERT, Ana Lúcia C. PASSOS, Eduardo. Pesquisa-intervenção como método, a formação como intervenção. In: BARROS, M.E.B; CARVALHO, S.; FERIGATO, S. (Org.). Conexões: saúde coletiva e políticas de subjetividade. 198ed. São Paulo: HUCITEC, 2009, v. 1, p. 376-393.

HOOKS, Bell. Ensinando a transgredir: a educação como prática de liberdade. 2. ed. São Paulo: WMF Martins Fontes, 2017.

HOOKS, Bell. Não sou eu uma mulher: Mulheres negras e feminismo. $1^{\mathrm{a}}$ ed. Editora Record, Rio de Janeiro, 2019.

KILOMBA, Grada. Memórias da plantação: episódios de racismo cotidiano. Rio de Janeiro: Cobogó, 2019.

LAPOUJADE, David. Fundar a violência: uma mitologia? In: NOVAES, A. (Org.). Mutações: fontes passionais da violência da violência. São Paulo: Sesc, 2015, p. 79-94.

Acesso

em

03/07/2018: https://laboratoriodesensibilidades.wordpress.com/2017/05/15/a-violencia-naoexiste-david-lapoujade/

RIBEIRO, Djamila. É preciso discutir porque a mulher negra é a maior vítima de estupro no Brasil. El país. São Paulo, 23 de julho, 2016.

SOARES, Lissandra Vieira; MACHADO, Paula Sandrine. "Escrevivências" como ferramenta metodológica na produção de conhecimento em Psicologia Social. Rev. psicol. polít., São Paulo , v. 17, n. 39, p. 203-219, ago. 2017

Disponível em $<$ http://pepsic.bvsalud.org/scielo.php?script=sci_arttext\&pid=S1519549 X2017000200002\&lng=pt\&nrm=iso >. acessos em 28 out. 2020

OYĚWÙMÍ, Oyèrónké. Conceituando o gênero: os fundamentos eurocêntricos dos conceitos feministas e o desafio das epistemologias africanas. Tradução para uso didático de: OYĚWÙMÍ, Oyèrónké. Conceptualizing Gender: The Eurocentric Foundations of Feminist Concepts and the challenge of African Epistemologies. African Gender Scholarship: Concepts, Methodologies and Paradigms. CODESRIA Gender Series. Volume 1, Dakar, CODESRIA, p. 1-8, 2004.

PEZZATO, Luciane M.; L'ABBATE, Solange. O uso de diários como ferramenta de intervenção da Análise Institucional: potencializando reflexões no cotidiano da Saúde Bucal Coletiva. Physis, Rio de Janeiro , v. 21, n. 4, p. 12971314, Dec. 2011 . Available from <http://www.scielo.br/scielo.php?script=sci_arttext\&pid=S0103- 
$73312011000400008 \& \operatorname{lng}=\mathrm{en} \& \mathrm{nrm}=\mathrm{iso}>$.

access on 28 Oct. 2020. https://doi.org/10.1590/S0103-73312011000400008.

WERNECK, Jurema P. De Ialodês y Feministas. Reflexiones sobre la accion política de las mujeres negras em America Latina El Caribe.NouvellesQuestionsFéministes. Paris (1981), v. 24, p. 27-40, 2005.

Gabriela Silva Neves

Universidade Federal do Espírito Santo

E-mail: gabrielasilvanevess@gmail.com

Ana Lucia C. Heckert

Universidade Federal do Espírito Santo

E-mail: ana.heckert@gmail.com

\footnotetext{
${ }^{1}$ Conceição Evaristo é mestre em Literatura Brasileira pela PUC-Rio e Doutora em Literatura Comparada pela UFF. É autora de diversos contos coletivos e seis obras individuais (EVARISTO, 2018).

2 A pesquisa desta dissertação foi financiada pela Fundação de Amparo à Pesquisa do Espírito Santo (FAPES).

${ }^{3}$ Significa mulher em Iorubá.

${ }^{4}$ O Centro de Referência de Assistência Social (CRAS) é uma unidade de atenção básica dentro da Política Nacional de Assistência Social e representa o equipamento público da Assistência Social como uma política de Estado, conforme a Lei n. 12435/2011.

${ }^{5}$ É a constituição de "uma teoria abrangente do conhecimento que tem por objetivo identificar e investigar os critérios usados na avaliação do conhecimento" (COLLINS, 2019: 402).
} 